\title{
Preface for the article collection of "Multidisciplinary Researches on Deep Interiors of the Earth and Planets"
}

\author{
Satoru Tanaka ${ }^{1 *}$, Jonathan Aurnou² and Michael Bergman ${ }^{3}$
}

Keywords: Deep Earth, Planetary science, Core dynamics, Geodynamo, Core-mantle boundary, Inner core boundary, Seismology

\section{Preface}

Study of the Earth's Deep Interior (SEDI) is an international scientific organization and a Union Commission of the International Union of Geodesy and Geophysics, whose primary role is exchange and encouragement of knowledge and ideas about deep Earth studies through a biennial international symposium. The 14th SEDI symposium (SEDI2014) was held in Shonan Village Center, Kanagawa, Japan, from 3 to 8 August 2014. The logo mark and group photo are shown in Figs. 1 and 2, respectively. SEDI2014 was successfully organized by a Local Organizing Committee led by Hisayoshi Shimizu (Chair), Masataka Matsushima, Takashi Nakagawa (Program Chair), Masayuki Obayashi, Futoshi Takahashi, Nozomu Takeuchi, and Satoru Tanaka. About 150 participants including about 40 students attended, coming from fourteen different countries (Australia, Canada, China, Denmark, France, Germany, India, Japan, Netherland, Norway, Switzerland, Taiwan, UK, and USA).

As is usually the case with SEDI symposia, it was organized into eight sessions led by discussion leaders. These eight sessions were: S1, mantle-observations; S2, mantle-modeling and dynamics; S3, the core-mantle boundary; S4, inner core; S5, outer core-observations, S6, outer core-dynamics; S7, experiments; and S8, other planets. Highlights of the meeting included the Zatman Lecture on "Geomagnetic implications of inner core translation" by Jon Mound (University of Leeds) and the awarding of the Doornbos Prizes for outstanding work

\footnotetext{
* Correspondence: stan@jamstec.go.jp

${ }^{1}$ Department of Deep Earth Structure and Dynamics Research, Japan Agency for Marine-Earth Science and Technology, Yokosuka 237-0061, Japan Full list of author information is available at the end of the article
}

by three beginning scientists to Nick Schmerr, Kenji Ohta, and Binod Sreenivasan.

This article collection is intended to gather various papers from multidisciplinary presentations at SEDI2014, for which a schematic image is shown in Fig. 3, and comprises three reviews and five research papers primarily from planetary and Earth's core dynamics and seismology. Adams et al. (2015) review liquid sodium geodyamo experiments especially focusing on spherical Couette devices. Only the sodium experiments can achieve Earth-like values for the Raynolds and the magnetic Raynolds numbers. Thus, they note that the experiment can benchmark numerical simulations. Amit et al. (2015) review the effects of various core-mantle boundary $(\mathrm{CMB})$ heat flux patterns including its time dependency on planetary dynamos, which may be caused by a giant impact or complex lateral and temporal variations at the base of the mantle. They show that numerical dynamo with time-dependent $\mathrm{CMB}$ heat flux can explain the history of geomagnetic reversal frequency. Breuer et al. (2015) review growth models of planetary inner cores, e.g., iron snow and crystal floats, by using improved Fe-FeS phase diagrams and melting relation. They imply that iron snow can be a dynamo mechanism for the Moon, Mercury, and Ganymede and likely for Mars and that FeS crystallization can occur not only at the ICB but also at the CMB, in the core. Kuang and Tangborn (2015) examine the responses of core surface flows for global geomagnetic field models by assimilation of the Gauss coefficients of the core field and its secular variation. The result shows that the dynamo model spin-up process is shortened by the assimilation of the secular variation and that the strongest responses occur in flow beneath the $\mathrm{CMB}$ with the relatively small 


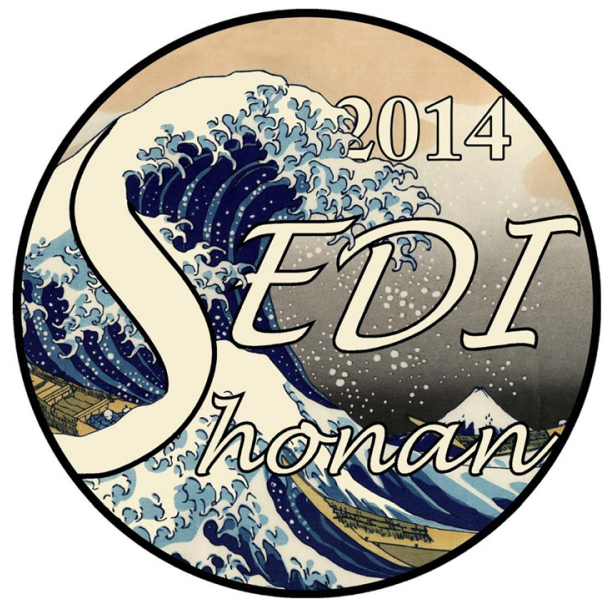

Fig. 1 The logo mark of SEDI2014 (courtesy of M. Obayashi)

scale. Soderlund et al. (2015) test force balance in the fluid motion within planetary cores by numerical experiments. They show that the Lorentz and Coriolis forces are comparable in the Earth's and Jovian core, and that the Lorentz force is weak in the cores of Saturn, Uranus, Neptune, Ganymede, and Mercury. Dietrich et al. (2015) discuss effects of thermal anomalies at the $\mathrm{CMB}$ (CMB hotspots) on planetary dynamos and imply that a possible Martian hemispherical dynamo cannot explain the dichotomy observed in the crustal magnetization on Mars. Kaneshima and Matsuzawa (2015) confirm the existence of a slightly low velocity region in the uppermost $300 \mathrm{~km}$ of the outer core by SmKS phases observed by seismic arrays around the world. They estimate that the pressure derivative of the bulk modulus in the concerned region is too large to be a purely thermal origin. Tanaka and Tkalčić (2015) report the frequency characteristics of the reflection coefficients of a seismic wave at the inner core boundary (ICB) and its regional change. They discuss the various nature of the ICB, e.g.,

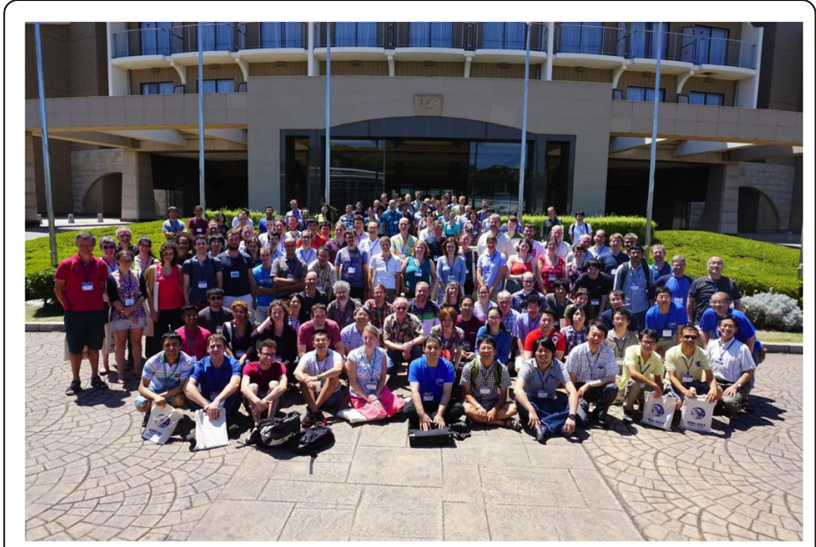

Fig. 2 Group photo of SEDI2014

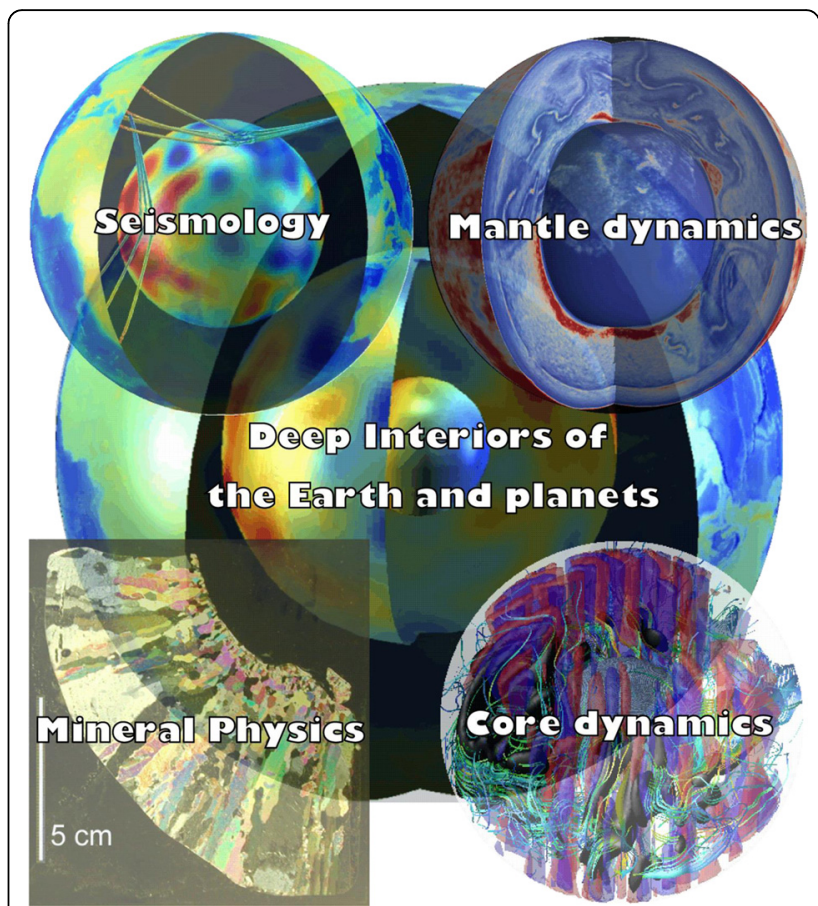

Fig. 3 Schematic image of multidisciplinary studies on deep interiors of the Earth and planets

topography and layering, and finally suggest that the existence of laterally varying ICB topography is a sign of lateral variation of inner core solidification.

It is our hope that this collection of articles will further the study of the deep Earth and planetary interiors, providing a long-lasting impact of the SEDI2014 international symposium.

\section{Abbreviations}

CMB: core-mantle boundary; ICB: inner core boundary.

\section{Competing interests}

The authors declare that they have no competing interests.

\section{Authors' contributions}

ST wrote the draft of this manuscript and others rewrote and confirmed the contents. All authors read and approved the final manuscript.

\section{Authors' information}

ST is Deputy Director and Senior Scientist at the Department of Deep Earth Structure and Dynamics Research, Japan Agency for Marine-Earth Science and Technology. JA is a professor at the Department of Earth, Planetary, and Space Sciences, University of California, Los Angeles. MB is a professor at Physics Department, Bard College at Simon's Rock.

\section{Acknowledgements}

SEDI2014 was supported by the Science Council of Japan, funding for the meeting came from IUGG, the US NSF, INSU/CNRS (France), the Japan Geoscience Union (JpGU) and its journal "Progress in Earth and Planetary Science" (PEPS), and the Inoue Foundation for Science (Japan). We would like to thank the invited speakers for the excellent talks that were given, the discussion leaders for leading fruitful discussions, and the general contributors for their outstanding posters and attending general discussions. All the participants thank Kaori Sugawara, a representative personnel of Shonan Village Center. She kindly hosted all the participants and organized a fantastic conference dinner in a 
traditional Japanese style and interesting excursion tours that introduced the participants to traditional and natural sites in Japan.

\section{Author details}

'Department of Deep Earth Structure and Dynamics Research, Japan Agency for Marine-Earth Science and Technology, Yokosuka 237-0061, Japan.

${ }^{2}$ Department of Earth, Planetary, and Space Sciences, University of California, Los Angeles, 595 Charles Young Drive East, Los Angeles, CA 90095-1567, USA. ${ }^{3}$ Physics Department, Bard College at Simon's Rock, Great Barrington, MA 01230, USA.

Received: 3 February 2016 Accepted: 3 February 2016

Published: 17 February 2016

\section{References}

Adams MM, Stone DR, Zimmerman DS, Lathrop DP (2015) Liquid sodium models of the Earth's core. Prog Earth Planet Sci 2:29. doi:10.1186/s40645-015-0058-1

Amit H, Choblet G, Olson P, Monteux J, Deschamps F, Langlais B, Tobie G (2015) Towards more realistic core-mantle boundary heat flux patterns: a source of diversity in planetary dynamos. Prog Earth Planet Sci 2:26. doi:10.1186/s40645-015-0056-3

Breuer D, Rueckriemen T, Spohn T (2015) Iron snow, crystal floats, and inner-core growth: modes of core solidification and implications for dynamos in terrestrial planets and moons. Prog Earth Planet Sci 2:39. doi:10.1186/s40645015-0069-y

Dietrich W, Wicht J, Hori K (2015) Effect of width, amplitude, and position of a core mantle boundary hot spot on core convection and dynamo action. Prog Earth Planet Sci 2:35. doi:10.1186/s40645-015-0065-2

Kaneshima S, Matsuzawa T (2015) Stratification of earth's outermost core inferred from SmKS array data. Prog Earth Planet Sci 2:15. doi:10.1186/s40645-0150046-5

Kuang W, Tangborn A (2015) Dynamic responses of the Earth's outer core to assimilation of observed geomagnetic secular variation. Prog Earth Planet Sci 2:40. doi:10.1186/s40645-015-0071-4

Soderlund KM, Sheyko A, King EM, Aurnou JM (2015) The competition between Lorentz and Coriolis forces in planetary dynamos. Prog Earth Planet Sci 2:24. doi:10.1186/s40645-015-0054-5

Tanaka S, Tkalčić H (2015) Complex inner core boundary from frequency characteristics of the reflection coefficients of PKiKP waves observed by Hi-net. Prog Earth Planet Sci 2:34. doi:10.1186/s40645-015-0064-3

\section{Submit your manuscript to a SpringerOpen ${ }^{\circ}$ journal and benefit from:}

- Convenient online submission

- Rigorous peer review

- Immediate publication on acceptance

- Open access: articles freely available online

High visibility within the field

- Retaining the copyright to your article 